\title{
Development of a short questionnaire based on the Practice Environment Scale-Nursing Work Index in primary health care
}

\author{
Vicente Gea-Caballero ${ }^{1,2}$, Raúl Juárez-Vela ${ }^{\text {Corresp., }{ }^{3,4} \text {, Miguel-Ángel Díaz-Herrera }}{ }^{5,6}$, Maribel Mármol-López ${ }^{1,7}$, Rubén \\ Alfaro-Blázquez ${ }^{7,8}$, José Ramón Martínez-Riera ${ }^{9}$ \\ 1 Nursing School La Fe, Universidad de Valencia, Valencia, Spain \\ 2 GREIACC, Instituto de Investigación Sanitaria IIS La Fe, Valencia, Spain. \\ 3 Facultad de Ciencia y Tecnología, Universidad de La Rioja, Logroño, Spain \\ 4 Instituto de Investigación Sanitaria de Aragón IIS-A, Logroño, Aragón, Spain \\ 5 Primary Care Nursing team Sant Ildefons-Cornellà 2, Institut Català de la Salut, Barcelona, Spain \\ 6 Knowledge Mobilisation Unit, Hospital Universitari General de Catalunya, Barcelona, Spain \\ 7 GREIACC, Instituto de Investigació Sanitaria IIS La Fe, Valencia, Spain. \\ 8 Hospital Universitari i Politècnic La Fe, Valencia, Spain \\ 9 Departamento de Enfermería Comunitaria, Medicina Preventiva y Salud Pública e Historia de la Ciencia, Facultad de Ciencias de la Salud, Universidad de \\ Alicante, Alicante, Spain \\ Corresponding Author: Raúl Juárez-Vela \\ Email address: raul.juarez@unirioja.es
}

Background Professional nursing environments determine the quality of care and patient outcomes. Assessing the quality of environments is essential to improve and obtain better health outcomes. Simplifying and shortening the way to evaluate environments reliably is also important to help nurses better understand the strengths and weaknesses of their environments. In that sense, identifying essential elements of nursing environments would allow the construction of short assessment tools to improve such environments. Objective: To construct a short tool to assess primary health care (PHC) nursing environments based on the Practice Environment Scale-Nursing Work Index (PES-NWI) questionnaire. Methods Observational, cross-sectional, analytical study (data collection February-April 2015). Tool: PES-NWI (31 items). Population: PHC nurses (3 health districts in Valencia, Spain) with more than 3 months in the organization. The nurses were asked to select the 10 elements of the questionnaire (items) that they considered key to facilitate and improve professional care, establishing as a final selection criterion that they obtain a global election $>40 \%$.Variables: sociodemographic and 31 questionnaire items. Analysis: descriptive statistics, reliability, multidimensional scaling (ALSCAL), factor analysis, multiple linear regression. Finally, we have analyzed the concordance between both measurements (TOP10 score on the full scale score) using the Bland-Altman method. Results Study sample $=269$ (Response rate $=80.29 \%$ ). Ten elements were identified based on selection frequency of the questionnaire PES-NWI. A factorial analysis explained $62.1 \%$ of variance, 
internal structure of 3 dimensions: 1- Participation in leadership and management, 2Nursing foundations for quality of care, 3- Adequacy of resources, with Acumulate Variance explained: Component 1: 24\%; Component 2: 43.1\%; Component 3: $62.1 \%)$. Reliability (Cronbach's Alpha) was 0.816 for short questionnaire, and $>0.8$ for all measurements. Stress $=0.184$ and $\mathrm{RSQ}=0.793$. Bland-Altman method: the scaling tends to be 1.92 points higher (equivalent to a maximum deviation of $1.54 \%$ ) than the full PES-NWI score (max score on PES-NWI=124 points). Conclusions It is possible to identify essential elements of environments to construct a short tool that simplifies the study of PHC environments. Conducting rapid studies of environments will provide managers with information about specific elements that require prioritisation to enhance quality of care and safety. 
1 Development of a short questionnaire based on the Practice Environment Scale-Nursing

2 Work Index in primary health care.

3

4

5 Vicente Gea-Caballero ${ }^{1}$, Raúl Juárez-Vela ${ }^{2}$, Miguel-Ángel Díaz-Herrera ${ }^{3}$, Maribel Mármol-

6 López ${ }^{1}$, Rubén Alfaro-Blázquez ${ }^{4}$, José Ramón Martínez-Riera ${ }^{5}$

7

81 Nursing School La Fe, Universidad de Valencia, Valencia, Spain; GREIACC, Instituto de 9 Investigación Sanitaria IIS La Fe, Valencia, Spain. Investigación Sanitaria de Aragón IIS-A, Logroño, Aragón, Spain.

3 Primary Care Nursing team Sant Ildefons-Cornellà 2, Institut Català de la Salut, Barcelona, Spain; Knowledge Mobilisation Unit, Hospital Universitari General de Catalunya, Barcelona, Spain.

4 Hospital Universitari I Politècnic La Fe, Valencia, Spain; GREIACC, Instituto de Investigación Sanitaria IIS La Fe, Valencia, Spain.

5 Departamento de Enfermería Comunitaria, Medicina Preventiva y Salud Pública e Historia de la Ciencia, Facultad de Ciencias de la Salud, Universidad de Alicante, Alicante, Spain.

\section{Corresponding author}

Dr. Raúl Juárez Vela.

C/Madre de Dios, 53. 26009, Logroño (La Rioja, España).

Email: raul.juarez@unirioja.es 
31 Background Professional nursing environments determine the quality of care and patient

outcomes. Assessing the quality of environments is essential to improve and obtain better health outcomes. Simplifying and shortening the way to evaluate environments reliably is also important to help nurses better understand the strengths and weaknesses of their environments. In that sense, identifying essential elements of nursing environments would allow the construction of short assessment tools to improve such environments. Objective: To construct a short tool to assess primary health care (PHC) nursing environments based on the Practice Environment Scale-Nursing Work Index (PES-NWI) questionnaire.

Methods Observational, cross-sectional, analytical study (data collection February-April 2015). Tool: PES-NWI (31 items). Population: PHC nurses (3 health districts in Valencia, Spain) with more than 3 months in the organization. The nurses were asked to select the 10 elements of the questionnaire (items) that they considered key to facilitate and improve professional care, establishing as a final selection criterion that they obtain a global election $>40 \%$. Variables: sociodemographic and 31 questionnaire items. Analysis: descriptive statistics, reliability, multidimensional scaling (ALSCAL), factor analysis, multiple linear regression. Finally, we have analyzed the concordance between both measurements (TOP10 score on the full scale score) using the Bland-Altman method.

Results Study sample=269 (Response rate=80.29\%). Ten elements were identified based on selection frequency of the questionnaire PES-NWI. A factorial analysis explained $62.1 \%$ of variance, internal structure of 3 dimensions: 1- Participation in leadership and management, 2Nursing foundations for quality of care, 3- Adequacy of resources, with accumulate variance explained: Component 1: 24\%; component 2: 43.1\%; component 3: 62.1\%). Reliability 
53 (Cronbach's Alpha) was 0.816 for short questionnaire, and $>0.8$ for all measurements.

54 Stress $=0.184$ and $\mathrm{RSQ}=0.793$. Bland-Altman method: the scaling tends to be 1.92 points higher

55 (equivalent to a maximum deviation of 1.54\%) than the full PES-NWI score (max score on PES-

$56 \mathrm{NWI}=124$ points).

57 Conclusions It is possible to identify essential elements of environments to construct a short tool

58 that simplifies the study of PHC environments. Conducting rapid studies of environments will

59 provide managers with information about specific elements that require prioritisation to enhance

60 quality of care and safety.

61

62

63

64

65

66

67

68

69

70

71

72

73

74

75 


\section{Introduction.}

Organisation can be understood as the "process of associating or combining groups that must carry out specific envisaged actions, with the appropriate and necessary means, in order to work in a sensible, rational and coordinated manner that facilitates goal achievement" (Mompart García \& Durán Escribano, 2009). Thus, nursing care does not occur in an organisational vacuum, but is the product of interaction between professionals, patients, the public, and the health service. One aspect of this interaction is the professional practice environment for nursing, which the International Council of Nurses (Baumann, 2007) has defined as "those settings that facilitate excellence and conscientious work... to ensure the health, safety and well-being of staff, promote quality patient care and improve motivation, productivity and outcomes". The study of nursing practice environments began with what is now considered a historic study on magnetism and health (McClure, Poulin, Sovie, \& Wandelt, 1983), and since then, significant associations have been found between optimal professional nursing practice environments and quality of care and more positive outcomes for users or patients (Copanitsanou, Fotos, \& Brokalaki, 2017). Excellent nursing environments yield specific benefits such as higher quality care (Kramer \& Schmalenberg, 2008; Schmalenberg \& Kramer, 2008; Trinkoff et al., 2010), lower rates of mortality, adverse events and work accidents (Aiken et al., 2014; Trinkoff et al., 2010), greater autonomy and professional development of clinical nurses (Kramer \& Schmalenberg, 2008), lower rates of turnover, absenteeism and vacancies in the nursing team

97 (Jones \& Gates, 2007), greater staff loyalty to the organisation and greater professional satisfaction (Hickson, 2013; Kelly, McHugh \& Aiken, 2011), significantly lower costs and 99 reduced administrative expenditure (Tai \& Bame, 2017). 
100 Many instruments have been developed to study and monitor nursing practice environments

101 (Norman, 2017), including the Practice Environment Scale of the Nursing Work Index (PES-

102 NWI) (A.1), developed by Lake in the USA (Lake, 2002), originally with 32 items and 5

103 dimensions. The five subscales have been shown to have an acceptable internal consistency and

104 reliability (Cronbach's Alpha min 0.807, and max 0.916) (Lake, 2002). This measures the

105 characteristics of professional environments, defined as "the organisational characteristics that

106 facilitate or constrain professional nursing practice". The author assessed 7 instruments and 54

107 studies of multidimensional instruments, and concluded that the PES-NWI was the most useful

108 instrument in this respect, whilst acknowledging that none of them was brief or swift to

109 administer. It has also been suggested that the Practice (PES-NWI) presents greater

110 methodological strength than the other tools available (Alzate, Bayer, \& Squires, 2014;

111 Gajewski, Boyle, Miller, Oberhelman, \& Dunton, 2010) and is considered by most authors as the

112 ideal instrument for assessing environments (Bonneterre, Liaudy, Chatellier, Lang, \& de

113 Gaudemaris, 2008). A more recent review also recommends its use, highlighting its "satisfactory

114 psychometric performance, high discriminant ability, and opportunity for comparison across

115 studies” (Swiger, Patrician, Miltnerc, Rajud, Breckenridge-Sproate, \& Loanf, 2017). In short,

116 this questionnaire has contributed to the development of safe work environments and quality,

117 efficient nursing practice (Gu \& Zhang, 2014), and has been validated in various cultural and

118 geographical contexts (Liou \& Cheng, 2009; Sermeus et al., 2011). In Spain, the questionnaire

119 was initially validated and adapted for general nursing environments with registered nurses (with

1201 item less than the original scale) (De Pedro Gómez et al., 2009) and later specifically for

121 Primary Health Care (PHC) (De Pedro-Gómez et al., 2012). Recently, it was also assessed for

122 content validity in 33 public hospitals in the Spanish national health system (Fuentelsaz-Gallego, 
123 Moreno-Casbas, \& González-María, 2013). The studies conducted in Spain have mainly focused

124 on appraising the quality of care environments in primary care. At an organisational level,

125 primary and community care in Spain is arranged differently to hospital care. These differences

126 are also found in the United States, where home care agencies with better-rated professional

127 work environments offer better patient care (Jarrin, Kang, \& Aiken 2017). Nurses are much more

128 independent, manage community health, and practise within community health centres and

129 patients' own homes (Jarrín, Flynn, Lake, \& Aiken, 2014). Previous studies have shown,

130 however, that some of the organisational characteristics present in hospital care can be equally

131 important in community care, influencing care excellence and clinical outcomes for patients

132 (Flynn, 2007; Jarrín, Flynn, Lake, \& Aiken, 2014).

133 In relation to the elements measured in environment assessment questionnaires, the essential

134 elements for professional practice have been defined as "those which nurses themselves

135 recognise as very important or significant for enhancing care in the pursuit of continuous

136 improvement and excellence" (Kramer \& Schalenberg, 2004), and various elements may be more

137 essential than others to improve care, such as the leadership of the coordinator, interprofessional

138 relations and the nurse's empowerment within the organisation (Anzai, Douglas, \& Bonner,

139 2014; Van den Heede et al., 2013), even in a study about community-based settings (Jarrín et al.,

140 2014; Mensik, 2006). The study by Mensik (Mensik, 2006) proposed that 10 elements were

141 crucial for community care delivery, in agreement with other investigations conducted in

142 hospitals (Kramer \& Schalenberg, 2004). Finally, a recent experience in Spain pointed out that

143 essential care elements could be identified by more than $40 \%$ of nurses (Gea-Caballero et al., 144 2017). 
145 Despite the organisational benefits derived from the use of the tool, the author of the original

146 questionnaire has identified the need for a short version of the PES-NWI as a priority

147 (questionnaires evaluating environments have gradually reduced in size) (Lake, 2002), together

148 with collecting further evidence about the questionnaire and assessing its performance in

149 different practice environments (Lake, 2007). Having a short version of any instrument facilitates

150 the exploration and collection of data, especially when exploring little or poorly studied

151 environments, such as PHC, since the results in these environments have been related to burnout,

152 satisfaction at work, quality of care and the intent to quit the job, postulated as essential

153 information for the restructuring of work processes in the primary health care environment

154 (Lorenz, 2014).

155 Therefore, our goal was to develop a short version of the questionnaire -facilitating and

156 simplifying data collection whilst maintaining the quality of the information obtained- by

157 identifying the essential elements of professional nursing practice environments in PHC, i.e.

158 those elements necessary to create optimal conditions for the provision of excellent nursing care

159 practice. A further goal was to assess the representativeness of essential items in relation to the

160 full PES-NWI questionnaire.

161

162 Materials \& Methods.

163 Study design: Observational, cross-sectional, multicentre and analytical study conducted in 2015,

164 in PHC units in the Xàtiva-Ontinyent, Elx-Crevillent and Torrevieja health districts (Valencia

165 region, Spain), serving a population of 615,000 citizens.

166 Population and sample: The study population comprised PHC nurses working in these health

167 districts. The questionnaire was sent to the entire population of nurses (estimating that the 
168 minimum number of responses to ensure the validity of the study was 198 , with CI 95\%, 5\%

169 error and a nursing population $\mathrm{N}=335$ ).

170 Inclusion and exclusion criteria: The inclusion criteria were: being a member of the health

171 district's permanent PHC staff, with $>3$ months in post. Exclusion criteria were: only nurses who

172 did not sign the informed consent to participate were excluded from the study.

173 Data were not collected during the summer months (July, August, September) to avoid the rise in 174 nurses employed temporarily to cover for those in permanent positions.

175 Data collection tool: We used the 31-item version of the PES-NWI questionnaire (A.p.1)

176 validated and adapted to PHC in Spain (reliability: Cronbach's Alpha=0.913) (De Pedro-Gómez

177 et al., 2012). The tool was self-completed by individuals online (Google Forms ${ }^{\circledR}$ via corporate

178 emails). The PES-NWI encompasses 5 dimensions: Nurse participation in centre affairs (9

179 items), Nursing foundation for quality of care (10 items), Management and leadership of head

180 nurse (5 items), Adequate human resources to ensure quality of care (4 items), and Nurse-

181 Physician relationship (3 items). Data collection and analysis were carried out by different pairs

182 of researchers to ensure impartiality. Researchers did not know the identity of participants.

183 Study variables: The sociodemographic variables collected were age (in years), gender (male,

184 female), level of education (diploma, degree, specialist qualification, master's degree, doctorate),

185 professional experience (years: $<2,2-4 .<4-10,>10$ ), exercise of a management/leadership role

186 (yes/no), health district, and place of work (Xàtiva/Ontinyent, Torrevieja, Elx/Crevillent). Each

187 item in the questionnaire was presented as a dichotomous qualitative study variable (Nurses were

188 asked to select the most important items to improve the care provided by them in primary health

189 care: 'Yes, it is essential' / 'No, it is not essential'). Which items from the PES-NWI are

190 considered an 'element' for the purposes of our study: we considered an element to be essential 
191 if it was indicated by a minimum of $40 \%$ of the study population (Gea-Caballero et al., 2017).

192 This was also partly because previous studies in the USA had also adopted a similar top-ten

193 approach (Mensik, 2006; Kramer \& Schalenberg, 2004). The variables were grouped into the

194 original dimensions of the PES-NWI questionnaire.

195 Data analysis: The statistical analysis (alpha=.05) was performed with SPSS v21. In terms of

196 descriptive statistics (\%), the global reliability of the survey tool as well as all the resulting sub-

197 scales was measured using Cronbach's alpha. Construct validity was measured using exploratory

198 factor analysis with analytical validation of the degree of correlation between the variables

199 (Kaiser-Meyer-Olkin, KMO) and Barlett's test of sphericity. Factor analysis measured the total

200 variance explained by the essential elements ('TOP10') obtained, using principal component

201 analysis (Varimax-Kaiser rotation). Confirmatory analysis was conducted using

202 multidimensional scaling (ALSCAL, with measure of S-stress and RSQ). Finally, the

203 concordance between both measurements was analysed using the Bland-Altman method.

204 Ethical aspects: Data were anonymised and protected according to relevant Spanish and

205 European legislation (Organic Law 15/1999, European Directive 95/46/CE). The Ethics

206 committee approved the study, and participants were provided with an information sheet and

207 were required to sign a consent form. The authors declare no conflict of interest or funding. This

208 research did not receive any specific grants from funding agencies in the public, commercial, or

209 not-for-profit sectors.

210

211 Results.

212 Descriptive results. 
213269 nurses completed the survey (response rate 80.29\%). The majority of participants were 31 -

21440 years of age (33.1\%); only $16.7 \%$ of participants were younger than 30 , and $30.1 \%$ were in

215 the 51-60 age bracket. $64.7 \%$ were women. $75.5 \%$ had more than 5 years' experience in primary

216 care, and $44.6 \%$ had more than 10 years' experience. In terms of educational achievement,

$21779.6 \%$ nurses were university educated. Only 10.4\% were managers or charge nurses.

218 The results are presented in Figure 1, which identifies the 10 most essential items (TOP10)

219 according to the ratings provided by the nurses surveyed. The cut-off at 10 items was partly

220 determined by the nurses' ratings, as there was a large gap between the preference for items 10

221 and 11; this figure was perceived to be crucial according to the participants, receiving $6.9 \%$ more

222 selections when compared to the following element (between the last item selected from the top

223 ten and the eleventh item, there is a difference in the percentage of elections of $6.9 \%$ ).

224

225 Figure 1.

226

227 Analysis results.

228 A factor analysis of the results for the full questionnaire, exploring rotated components

229 (Varimax-Kaiser rotation), reproduced the original structure of the full questionnaire in 5

230 dimensions.

231 A factor analysis of the 10 essential elements, which we call the 'TOP10', explained $62.79 \%$ of

232 the variance in 3 components (Accumulated Variance: Component 1: 24.96\%; Component 2:

233 43.97\%; Component 3: 62.79\%).

234 To determine construct validity, additional exploratory factor analysis was carried out for the

235 latent variables in the questionnaire, applying principal component analysis (PCA). The result of 
236 the Kaiser-Meyer-Olkin (KMO) test was 0.77. Bartlett's test of sphericity was statistically

237 significant $(\mathrm{p}<0.001)$, chi-square $=1473.9$. The results achieved in the non-parametric test to

238 perform multidimensional scaling as alternative to the confirmatory factor analysis obtains stress

239 values $=0.184$ and RSQ coefficient $=0.793$. Varimax-Kaiser rotation of the 10 essential

240 components indicated an internal structure of 3 dimensions (Table 1).

242 Table 1

243

244 Reliability was determined using Cronbach's alpha (entire questionnaire $=0.943$ ), and for the 5

245 questionnaire dimensions (D1 to D5), with all measurements obtaining $>0.8$ (D1=0.87; D2=0.85;

246 D3=0.93; D4=0.84; D5=0.81). The reliability coefficient (Cronbach) for all of the TOP10

247 questionnaire items combined was 0.816 . The Cronbach values for the dimensions of the short

248 questionnaire were D1=.727; D2=0.705; D3=0.899. Below, we present the TOP10 essential

249 elements for quality care grouped into 3 dimensions, and define the dimensions (Table 2).

250

251 Table 2.

252

253 We explored the predictive and explanatory power of the TOP10 in relation to the overall PES-

254 NWI score in our sample (Table 3) using multiple linear regression. We found that the short scale 255 closely predicted the overall scores obtained using the PES-NWI.

256

257 Table 3

258 
259 Finally, we analysed the concordance between both measures (PES-NWI and TOP10) using the

260 Bland-Altman method. Previously it was found that the distribution was Gaussian and that it

261 fulfilled all the conditions required to apply the method.

262 The scaling (TOP10 score on the full scale) tends to be 1.92 points higher (equivalent to a 263 maximum deviation of $1.54 \%$ ) than the full PES-NWI score (max score on PES-NWI=124 points).

264 The maximum differences in $95 \%$ of the cases are between -14.6 and 10.76 points. The bias of the 265 TOP10 with respect to the PES-NWI is, therefore, 1.92 points (Figure 2).

Figure 2.

\section{Discussion.}

270 We aimed to synthesise and prioritise the essential elements for improving PHC, using the

271 Spanish version of the PES-NWI questionnaire as a basis to construct a short nursing

272 environment assessment tool. The TOP10 presents an internal structure centred around 3

273 dimensions, and the reliability -internal consistency- of the short questionnaire and its

274 dimensions is confirmed according to Cronbach's original criteria for short questionnaires

275 (Cronbach, 1951). The psychometric tests performed, including Bartlett's test of sphericity and

276 Kaiser-Meyer, are within the intervals accepted in the literature to measure construct validity

277 (Kaiser, 1974). When the multidimensional scaling technique was used as a non-parametric

278 alternative to confirmatory factor analysis (Porcar Gómez \& Escalante Gómez, 2009) we also

279 obtained acceptable stress values. In addition, the Bland-Altman method has given a result that

280 we consider good, with a high prediction power from the TOP10, in relation to the complete

281 PES-NWI questionnaire. Overall, and based on these psychometric results, we propose a short, 
282 'TOP10' questionnaire based on the PES-NWI. If additional studies consolidate these findings, it

283 could be a short, quick and flexible alternative option for the study and assessment of

284 professional nursing work environments.

285 The acceptable percentage of variance explained by these 10 elements, together with the

286 antecedents that already affirmed that there could be 10 key elements to explore nursing work

287 environments (Mensik, 2006, 2007; Schmalenberg \& Kramer, 2008; Gea-Caballero et al., 2017),

288 support our focus on detecting the 10 most significant elements for nurses.

289 Our results are in line with those obtained by Mensik (Mensik, 2006, 2007) for home-care

290 environments in the United States. Thus, our essential elements coincided with at least 10 of the

291 elements proposed by Mensik: support from managers/administrators, focus on collaborative

292 practices and multidisciplinary roles, partnership with physicians, interprofessional relations,

293 promotion of professional competence, and control of contextual characteristics of the

294 environment, which would include adequate allocation of human resources, nurse training and

295 long-term allocation of patients to nurses (Aiken et al., 2008; Jarrín et al., 2014; Kieft, de

296 Brouwer, Francke, \& Delnoij, 2014). With respect to their applicability in different

297 environments, Mensik (Lake, 2002) has stated that the essential elements are probably common

298 to or very similar in settings as diverse as hospital, community or home-based care (Mensik,

299 2006). Consequently, we suggest that it would be relevant and appropriate to conduct

300 comparative research in different environments and cultures.

301 A study of hospital environments (Schmalenberg \& Kramer, 2008) using the Essentials of

302 Magnetism (EOM) tool has indicated the essential elements of magnetism: the authors found 10

303 essential elements, 8 of which accounted for most of the variance and were termed the essential

304 8. Our findings present a high degree of agreement with these results, on up to 7 items if the last 
305 item is analysed carefully, which includes both clinical competence and training support. A

306 recent study in Spain (Gea-Caballero et al., 2017) highlighted a number of essential elements that

307 agree with the TOP10 proposed in the current manuscript (Table 4).

308

309

Table 4.

310

311 In our study, the most important factor for improving care was nursing leadership, a finding that

312 coincides with most other studies (Jarrín et al., 2014; Mensik, 2006, 2007; Van den Heede et al.,

313 2013); these studies have also stressed the importance of other factors in our TOP10, e.g.

314 provision of adequate resources and good relationships between nurses/physicians.

315 This high level of agreement indicates that such consensus is not likely to be attributed to

316 chance. Rather, we believe it reflects a trend in the results of the studies carried out, suggesting

317 that, independently of the questionnaire employed or the environment studied, nurses tend to

318 consider certain elements of particularly important to improve nursing care.

319 The information obtained by isolating these 10 items from the questionnaire presented a high

320 predictive power $(90.7 \%)$ in relation to the overall score obtained with the full PES-NWI

321 questionnaire, and explained $62.79 \%$ of total variance, with a slight overestimation of $1.54 \%$

322 points according to the Bland-Altman method, which we consider acceptable, despite yielding

323 broad deviation. Consequently, using our proposed TOP10 tool at an operational level (research

324 and/or management) will yield a positive result because it provides a short, simple method to

325 rapidly obtain reliable information on the general characteristics of a professional nursing

326 environment. Future research is required to confirm and increase the evidence and to broaden it

327 to the field of hospital care.

Peer] reviewing PDF | (2018:11:33065:3:0:NEW 10 Jun 2019) 
328 Therefore, we propose a short tool with 3 dimensions selected for their central role in the

329 analysis of professional environments, and which include elements from all the dimensions in the

330 PES-NWI; the first dimension includes items related to leadership and management of healthcare

331 services; the second dimension relates to fundamentals of nursing for the quality of care and

332 relations with other professionals, an aspect related to independence for decision-making and

333 self-management of nursing practice (Burton, 2010); the third one refers to the availability of

334 human resources. Additionally, the developer of the original PES-NWI questionnaire (Lake,

335 2002) considers that the item 'relationships between nurses and physicians' can be confused with

336 autonomous practice in nursing, an aspect identified by other authors (Chouinard, 2017). In our

337 study, we defined that an 'adequate' relationship between nurses and doctors could refer to

338 autonomous practice and control over their sphere of practice (Kieft et al., 2014).

339 Construction of this short tool is in line with the recommendation of the author of the PES-NWI

340 questionnaire (Lake, 2007), who has stressed the importance of improving evidence on the scale

341 and constructing short versions for evaluating environments (our TOP10 proposal is

342 administered in $<2$ minutes), as well as implementing and testing it in different nursing practice

343 environments (PHC environments from Spain in our study, an under-researched work

344 environment). We advocate its use in pilot evaluations of primary care environments, as well as

345 once a complete picture of a given environment is ready, and following organisational changes in

346 order to evaluate their impact.

347 We believe that short tools for assessing environments, which simplify data collection, will

348 facilitate the evaluation and improvement of these. Consequently, the construction of a short tool

349 based on a questionnaire such as the PES-NWI, which has been widely adapted, translated and

350 used in many countries worldwide, is important to simplify the process of obtaining information 
351 about the most significant elements of nursing environments in order to facilitate the study and

352 improvement of nursing work environments.

353 Limitations: This study is exploratory. Therefore, additional studies of practice environments

354 with the new simplified and revised PES-NWI tool could yield further evidence concerning the

355 validity of the TOP10 essential elements and contribute to improving quality of care by

356 modifying these environments in order to create better conditions that make it possible to

357 continue optimising nursing care. It is necessary to improve the reliability of the TOP 10 , as well

358 as to reduce the deviations obtained for the short questionnaire measurements, since these are

359 high and must, therefore, be reduced.

360 We are aware that our TOP10 is an unsuitable choice if the goal is to obtain exhaustive

361 information on all 5 dimensions of the PES-NWI questionnaire, because it does not replicate the

362 original structure (dimensions) and, therefore, does not have the capacity to explain the

363 information in full. It yields equivalent information for dimensions 1, 2 and 4, but offers less

364 information for dimensions 3 and 5. This represents another limitation of the study, particularly

365 with regard to D5 (Nurse-Physician relationship), which is a short dimension. However, for D3

366 (leadership), we believe that the element we propose is fully representative of the dimension as a

367 whole, which could compensate for the loss of information obtained: a good leader and team

368 coordinator ought to support the staff, see mistakes as opportunities to improve, be

369 understanding and praise quality work.

371 Conclusions.

372 Our study identified ten key elements based on the items of the PES-NWI scale: those elements

373 of the environment that are especially relevant to professional nursing practice in PHC. This has 
374 enabled the development of a rapid environment assessment tool consisting of 10 items (TOP10),

375 which has shown acceptable predictive power regarding the full questionnaire.

376 Since professional environments and nursing activity are variable organisational factors, use of

377 this short tool will simplify data collection and facilitate decision-making for managers in

378 relation to improving quality and outcomes in the population.

379

380

381

382

383

384

385

386

387

388

389

390

391

392

393

394

395

396

397

398

Peer] reviewing PDF | (2018:11:33065:3:0:NEW 10 Jun 2019) 
401

402

403

404

405

406

407

408

409

410

411

412

413

414

415

416

417

418

419

420

421

422

423

424

425

426

427

428

429

430

431

432

433

434

435

\section{References.}

Aiken, L. H., Sloane, D. M., Bruyneel, L., Van den Heede, K., Griffiths, P., Busse, R., ... Sermeus, W. (2014). Nurse staffing and education and hospital mortality in nine European countries: a retrospective observational study. The Lancet, 383(9931), 1824-1830. https://doi.org/10.1016/S0140-6736(13)62631-8

Alzate, L. C. C., Bayer, G. L. A., \& Squires, A. (2014). Validation of a Spanish Version of the Practice Environment Scale of the Nursing Work Index in the Colombian Context. Hispanic Health Care International, 12(1), 34-42. https://doi.org/10.1891/1540-4153.12.1.34

Anzai, E., Douglas, C., \& Bonner, A. (2014). Nursing practice environment, quality of care, and morale of hospital nurses in Japan. Nursing \& Health Sciences, 16(2), 171-178. https://doi.org/10.1111/nhs.12081

Baumann, A. (2007). Entornos de práctica favorables: lugares de trabajo de calidad = atención de calidad al paciente. Conjunto de instrumentos para información y actuación. (CIE Consejo internacional de Enfermeras, Ed.) (1st ed.). Ginebra: CIE - Consejo internacional de Enfermeras.

Bonneterre, V., Liaudy, S., Chatellier, G., Lang, T., \& de Gaudemaris, R. (2008). Reliability, validity, and health issues arising from questionnaires used to measure Psychosocial and Organizational Work Factors (POWFs) among hospital nurses: a critical review. Journal of Nursing Measurement, 16(3), 207-230. https://doi.org/0.1891/1061-3749.16.3.207

Burton, J. (2010). WHO healthy workplace framework and model: background and supporting literature and practices. Geneva: World Health Organization (WHO). Retrieved from http://www.who.int/iris/handle/10665/113144

Chouinard, V., Contandriopoulos, D., Perroux, M., \& Larouche, C. (2017). Supporting nurse practitioners' practice in primary healthcare settings: a three-level qualitative model. BMC Health Services Research, 17(1), 437. doi: 10.1186/s12913-017-2363-4

Copanitsanou, P., Fotos, N., \& Brokalaki, H. (2017). Effects of work environment on patient and nurse outcomes. British Journal of Nursing, 26(3), 172-176. doi: 10.12968/bjon.2017.26.3.172.

Cronbach, L. J. (1951). Coefficient alpha and the internal structure of tests. Psychometrika, 16(3), 297-334.

De Pedro-Gómez, J., Morales-Asencio, J. M., Sesé-Abad, A., Bennasar-Veny, M., PericasBeltran, J., \& Miguélez-Chamorro, A. (2012). Psychometric testing of the Spanish version of the Practice Environment Scale of the Nursing Work Index in a primary healthcare

Peer) reviewing PDF | (2018:11:33065:3:0:NEW 10 Jun 2019) 
450

451

452

453

454

455

456

457

458

459

460

461

462

463

464

465

466

467

468

469

470

471

472

473

context. Journal of Advanced Nursing, 68(1), 212-221. Retrieved from http://www.ncbi.nlm.nih.gov/pubmed/21711384

De Pedro Gómez, J., José Miguel Morales, A., Albert Sesé, A., Bennasar Veny, M., Artigues Vives, G., \& Pericàs Beltran, J. (2009). Validación y adaptación al español de la escala del entorno de práctica enfermera del Nursing Work Index. Metas de Enfermería, 12(7), 65-75.

Flynn, L. (2007). Extending Work Environment Research Into Home Health Settings. Western Journal of Nursing Research, 29(2), 200-212. https://doi.org/10.1177/0193945906292554

Fuentelsaz-Gallego, C., Moreno-Casbas, M. T., \& González-María, E. (2013). Validation of the Spanish version of the questionnaire Practice Environment Scale of the Nursing Work Index. International Journal of Nursing Studies, 50(2), 274-280. https://doi.org/10.1016/j.ijngardnerurstu.2012.08.001

Gajewski, B. J., Boyle, D. K., Miller, P. A., Oberhelman, F., \& Dunton, N. (2010). A Multilevel Confirmatory Factor Analysis of the Practice Environment Scale. Nursing Research, 59(2), 147-153. https://doi.org/10.1097/NNR.0b013e3181d1a71e

Gea-Caballero, V., Castro-Sánchez, E., Júarez-Vela, R., Díaz-Herrera, M. Á., de MiguelMontoya, I., \& Martínez-Riera, J. R. (2017). Elementos esenciales de los entornos profesionales enfermeros en Atención Primaria y su influencia en la calidad del cuidado. Enfermería Clínica, 28(1), 27-35. https://doi.org/10.1016/j.enfcli.2017.07.008

Gu, L.-Y., \& Zhang, L.-J. (2014). Assessment tools of nursing work environment in magnet hospitals: A review. International Journal of Nursing Sciences, 1(4), 437-440. https://doi.org/10.1016/j.ijnss.2014.10.013

Hickson, J. (2013). New nurses' perceptions of hostility and job satisfaction. Journal Nursing Administration, 43(5), 293-301. doi: 10.1097/NNA.0b013e31828eebc9

Jarrín, O., Flynn, L., Lake, E. T., \& Aiken, L. H. (2014). Home Health Agency Work Environments and Hospitalizations. Medical Care, 52(10), 877-883. https://doi.org/10.1097/MLR.0000000000000188

Jarrin, O.F., Kang, Y., \& Haiken, L.H. (2017). Pathway to better patient care and nurse workforce outcomes in home care. Nursing Outlook, 65(6), 671-678. doi: https://doi.org/10.1016/j.outlook.2017.05.009

Jones, C.B., \& Gates M. (2007). The cost and benefits of nurse turnover: a business case for nurse retention. Online Journal Issues of Nursing, 12(3) Manuscript4. doi: 10.3912/OJIN.Vol12No03Man04

Kaiser, H. F. (1974). An index of factorial simplicity. Psychometrika, 39(1), 31-36. https://doi.org/10.1007/BF02291575

Kelly, L.A., McHugh, M.D., \& Aiken L.H. (2011). Nurse outcomes in Magnet and non-Magnet hospitals. Journal Nursing Administration, 41(10), 428-33. doi: 10.1097/NNA.0b013e31822eddbc

Kieft, R. A., de Brouwer, B. B., Francke, A. L., \& Delnoij, D. M. (2014). How nurses and their 
474

475

476

477

478

479

480

481

482

483

484

485

486

487

488

489

490

491

492

493

494

495

496

497

498

499

500

501

502

503

504

505

506

507

508

509

510

511

512

513

work environment affect patient experiences of the quality of care: a qualitative study. $B M C$ Health Services Research, 14(1), 249. Retrieved from http://www.ncbi.nlm.nih.gov/pubmed/24923663

Kramer, M., \& Schalenberg, C. (2004). Essentials of a magnetic work environment, part 1. Nursing, 34(6), 50-54. Retrieved from http://ovidsp.ovid.com/ovidweb.cgi?T $=\mathrm{JS} \& N E W S=\mathrm{n} \& \mathrm{CSC}=\mathrm{Y} \& \mathrm{PAGE}=$ fulltext $\& \mathrm{D}=\mathrm{ovft} \&$ $\mathrm{AN}=00152193-200406000-00043$

Kramer, M., \& Schmalenberg, C. (2008). The practice of clinical autonomy in hospitals: 20000 nurses tell their story. Critical Care Nurse, 28(6), 58-71. Retrieved from http://www.ncbi.nlm.nih.gov/pubmed/19047696

Lake, E. T. (2002). Development of the practice environment scale of the nursing work index. Research in Nursing \& Health, 25(3), 176-188. Retrieved from http://onlinelibrary.wiley.com/doi/10.1002/nur.10032/abstract

Lake, E. T. (2007). The Nursing Practice Environment. Medical Care Research and Review, 64(2_suppl), 104S-122S. https://doi.org/10.1177/1077558707299253

Liou, S.-R., \& Cheng, C.-Y. (2009). Using the Practice Environment Scale of the Nursing Work Index on Asian Nurses. Nursing Research, 58(3), 218-225. https://doi.org/10.1097/NNR.0b013e3181a308cd

Lorenz, V.R., Guirardello E.B. (2014). The environment of professional practice and Burnout in nurses in primary healthcare. Revista Latino Americana Enfermagem, 22(6), 926-33. doi: 10.1590/0104-1169.0011.2497

McClure, M. L., Poulin, M. J., Sovie, M., \& Wandelt, M. (1983). Magnet hospitals. Attraction and retention of professional nurses. Task Force on Nursing Practice in Hospitals. American Academy of Nursing. American Nurses Association Publications, (G-160), 1-135. Retrieved from http://www.ncbi.nlm.nih.gov/pubmed/6551146

Mensik, J. S. (2006). Describing essentials of magnetism and quality in home health (Dissertation). The University of Arizona. Retrieved from http://hdl.handle.net/10150/194049

Mensik, J. S. (2007). The Essentials of Magnetism for Home Health. JONA: The Journal of Nursing Administration, 37(5), 230-234. https://doi.org/10.1097/01.NNA.0000269742.40137.a6

Mompart García, M. P., \& Durán Escribano, M. (2009). Administración y gestión de servicios de enfermería. (D. A. de Enfermería, Ed.), Coleccion Enfermeria S21 (2nd ed., Vol. ADMINISTRA). Madrid.

Norman, R.M., \& Sjetne.I.S. (2017). Measuring nurses' perception of work environment: a scoping review of questionnaires. BMC Nursing, 16, 66. doi: 10.1186/s12912-017-0256-9

Porcar Gómez, M. L., \& Escalante Gómez, E. (2009). Límites de la explicación interna (norma de internidad). Análisis de Escalamiento Multidimensional. Revista Electrónica de Investigación y Docencia, 2, 59-77. Retrieved from http://revistaselectronicas.ujaen.es/index.php/reid/article/view/1107/931 
514 Schmalenberg, C., \& Kramer, M. (2008). Essentials of a Productive Nurse Work Environment.

515

516

517

518

519

520

521

522

523

524

525

526

527

528

529

530

531

532

533

534

535

536

537

538

539

540

541

542

543
Nursing Research, 57(1), 2-13. Retrieved from

http://ovidsp.ovid.com/ovidweb.cgi?T $=J S \& N E W S=$ n\&CSC $=$ Y \&PAGE $=$ fulltext\&D $=$ ovft $\&$ $\mathrm{AN}=00006199-200801000-00002$

Sermeus, W., Aiken, L. H., Van den Heede, K., Rafferty, A. M., Griffiths, P., Moreno-Casbas, M. T., ... Zikos, D. (2011). Nurse forecasting in Europe (RN4CAST): Rationale, design and methodology. BMC Nursing, 10(1), 6. https://doi.org/10.1186/1472-6955-10-6

Swiger, P.A., Patrician, P.A., Miltner, R.S., Rajud, D., Breckenridge-Sproate, S., \& Loanf, L.A. (2017). The Practice Environment Scale of the Nursing Work Index: An updated review and recommendations for use. International Journal Nursing Studies, 74, 76-84. doi: 10.1016/j.ijnurstu.2017.06.003

Tai, T.W., Bame, S.I. (2017). Organizational and Community Factors Associated With Magnet Status of U.S. Hospitals. Journal Healthcare Management, 62(1):62-76. Retrieved from https://www.ncbi.nlm.nih.gov/pubmed/28319992

Trinkoff, A. M., Johantgen, M., Storr, C. L., Han, K., Liang, Y., Gurses, A. P., \& Hopkinson, S. (2010). A Comparison of Working Conditions Among Nurses in Magnet $\AA$ and NonMagnet巴 Hospitals. JONA: The Journal of Nursing Administration, 40(7/8), 309-315. https://doi.org/10.1097/NNA.0b013e3181e93719

Van den Heede, K., Florquin, M., Bruyneel, L., Aiken, L., Diya, L., Lesaffre, E., \& Sermeus, W. (2013). Effective strategies for nurse retention in acute hospitals: A mixed method study. International Journal of Nursing Studies, 50(2), 185-194. https://doi.org/10.1016/j.ijnurstu.2011.12.001 
Table $\mathbf{1}$ (on next page)

Matrix of rotated component results (Varimax): TOP10.

${ }^{\text {aHighest score. }}$ 


\begin{tabular}{|c|c|c|c|c|}
\hline \multirow{2}{*}{$\begin{array}{c}\text { Number } \\
\text { original ítem }\end{array}$} & \multirow{2}{*}{$\begin{array}{c}\text { Essential elements (TOP10) of the } \\
\text { PES-NWI }\end{array}$} & \multicolumn{3}{|c|}{ Components } \\
\hline & & 1 & 2 & 3 \\
\hline 1 & $\begin{array}{l}\text { Nurses at the centre have } \\
\text { opportunities to participate in } \\
\text { decisions that affect centre policies. }\end{array}$ & $.753^{a}$ & -.098 & .195 \\
\hline 11 & $\begin{array}{l}\text { There is an active programme for } \\
\text { guaranteeing and improving quality. }\end{array}$ & $.666^{\mathrm{a}}$ & .327 & .118 \\
\hline 14 & $\begin{array}{l}\text { The allocation of patients to each } \\
\text { nurse promotes continuity of care } \\
\text { (e.g. the same nurse cares for the } \\
\text { patient over time). }\end{array}$ & -.104 & $.804^{a}$ & .183 \\
\hline 15 & $\begin{array}{l}\text { There is a common, well-defined } \\
\text { nursing philosophy that permeates the } \\
\text { patient care environment. }\end{array}$ & .411 & $.649^{a}$ & .207 \\
\hline 18 & $\begin{array}{l}\text { Nurses are offered continuing } \\
\text { education programmes. }\end{array}$ & $.639^{a}$ & .383 & -.058 \\
\hline 19 & $\begin{array}{l}\text { Nurses at the centre present } \\
\text { satisfactory clinical competence. }\end{array}$ & .410 & $.582^{\mathrm{a}}$ & -.079 \\
\hline 20 & $\begin{array}{l}\text { The supervisor/coordinator is a good } \\
\text { manager and leader. }\end{array}$ & $.685^{\mathrm{a}}$ & .163 & .214 \\
\hline 25 & $\begin{array}{l}\text { There are sufficient employees to do } \\
\text { the job properly. }\end{array}$ & .104 & .082 & $.939^{a}$ \\
\hline 26 & $\begin{array}{l}\text { There is a sufficient number of } \\
\text { qualified nurses to provide quality } \\
\text { care. }\end{array}$ & .224 & .206 & $.890^{\mathrm{a}}$ \\
\hline 31 & $\begin{array}{l}\text { Practice is based on appropriate } \\
\text { collaboration between nurses and } \\
\text { physicians. }\end{array}$ & .333 & $.401^{\mathrm{a}}$ & .197 \\
\hline
\end{tabular}




\section{Table 2 (on next page)}

Final structure of the scale, assigning essential items to a 3-dimensional structure.

Table 2 shows how the items are grouped in each dimension of the TOP10 questionnaire. 


\begin{tabular}{|c|c|c|c|}
\hline Dimension & Item & Item description & Normalisation \\
\hline \multirow{4}{*}{$\begin{array}{l}1 \\
\text { Participation in } \\
\text { management } \\
\text { and leadership }\end{array}$} & 1 & $\begin{array}{l}\text { Nurses at the centre have } \\
\text { opportunities to participate in } \\
\text { decisions that affect centre } \\
\text { policies. }\end{array}$ & .753 \\
\hline & 11 & $\begin{array}{l}\text { There is an active programme for } \\
\text { guaranteeing and improving } \\
\text { quality. }\end{array}$ & .666 \\
\hline & 18 & $\begin{array}{l}\text { Nurses are offered continuing } \\
\text { education programmes. }\end{array}$ & .639 \\
\hline & 20 & $\begin{array}{l}\text { The supervisor/coordinator is a } \\
\text { good manager and leader. }\end{array}$ & .685 \\
\hline \multirow{4}{*}{$\begin{array}{c}2 \\
\text { Focus on nursing } \\
\text { care and } \\
\text { interdisciplinary } \\
\text { relationships }\end{array}$} & 14 & $\begin{array}{l}\text { The allocation of patients to each } \\
\text { nurse promotes continuity of care } \\
\text { (e.g. the same nurse cares for the } \\
\text { patient over time). }\end{array}$ & .804 \\
\hline & 15 & $\begin{array}{l}\text { There is a common, well-defined } \\
\text { nursing philosophy that permeates } \\
\text { the patient care environment. }\end{array}$ & .649 \\
\hline & 19 & $\begin{array}{l}\text { Nurses at the centre present } \\
\text { satisfactory clinical competence. }\end{array}$ & .582 \\
\hline & 31 & $\begin{array}{l}\text { Practice is based on appropriate } \\
\text { collaboration between nurses and } \\
\text { physicians. }\end{array}$ & .401 \\
\hline 3 & 25 & $\begin{array}{l}\text { In general, there are sufficient } \\
\text { employees to do the job. }\end{array}$ & .939 \\
\hline $\begin{array}{l}\text { Adequate } \\
\text { resources }\end{array}$ & 26 & $\begin{array}{l}\text { There is a sufficient number of } \\
\text { qualified nurses to provide quality } \\
\text { care. }\end{array}$ & .890 \\
\hline
\end{tabular}

2 


\section{Table 3 (on next page)}

Total variance explained by the TOP10 with respect to the original scale.

Predictive and explanatory power of the TOP10 in relation to the overall PES-NWI score in our sample, using multiple linear regression. 
1

\begin{tabular}{lc}
\hline & $\begin{array}{c}\text { \% Variance explained* by the TOP10 } \\
\text { in relation to the original 5 dimensions }\end{array}$ \\
\hline Overall score & $90.7 \%$ \\
Participation in centre management & $74.7 \%$ \\
Focus on quality of care & $86.5 \%$ \\
Capacity, leadership and support of & $55.0 \%$ \\
managers & $85.1 \%$ \\
Human resources & $38.0 \%$ \\
Relationships between physicians and & \\
nurses & \\
\hline
\end{tabular}

2

3 


\section{Table 4 (on next page)}

Comparison of professional practice elements in hospital/home/community care (Kramer/Mensik/Gea 2018/Gea). Adapted from Mensik (2006).

Table 4 shows the comparison of essential elements found in different studies. We can observe the high stability in the elements considered essential. 


\begin{tabular}{|c|c|c|c|c|}
\hline $\begin{array}{c}\text { Organisational } \\
\text { attribute }\end{array}$ & $\begin{array}{l}\text { Staff nurses } \\
\% \text { (Kramer) }\end{array}$ & $\begin{array}{c}\text { HHCa } \\
\text { nurses } \\
\% \\
\text { (Mensik) }\end{array}$ & $\begin{array}{c}\% \text { Gea et al. } \\
2018\end{array}$ & $\begin{array}{l}\text { Top Ten } \\
\% \text { (Gea) }\end{array}$ \\
\hline $\begin{array}{l}\text { Working with other } \\
\text { nurses who are clinically } \\
\text { competent. }\end{array}$ & 80.1 & 72.6 & 39.6 & $44.5^{b}$ \\
\hline $\begin{array}{l}\text { Good nurse/doctor } \\
\text { relationships and } \\
\text { communication. }\end{array}$ & 79.2 & 60.4 & 43.8 & 56.3 \\
\hline $\begin{array}{l}\text { Nurse autonomy and } \\
\text { accountability. }\end{array}$ & 73.5 & 51.9 & $46.5^{c}$ & $(51.7)^{\mathrm{c}}$ \\
\hline $\begin{array}{l}\text { Supportive nurse } \\
\text { manager, supervisor. }\end{array}$ & 69.5 & 80.2 & 48.6 & 60.5 \\
\hline $\begin{array}{l}\text { Control over nursing } \\
\text { practice. }\end{array}$ & 68.9 & 13.2 & --- & --- \\
\hline Support for education. & 66.2 & 38.7 & 49.3 & 44.5 \\
\hline Adequate nursing staff. & 62.5 & 79.2 & 41 & 47.1 \\
\hline $\begin{array}{l}\text { Concern for patient is } \\
\text { paramount. }\end{array}$ & 62.0 & 89.6 & 45.8 & 46 \\
\hline Flexible work schedule. & --- & 67.9 & --- & --- \\
\hline Continued competency. & --- & 44.3 & 49.3 & 44.5 \\
\hline $\begin{array}{l}\text { Adequate support } \\
\text { services. }\end{array}$ & --- & 41.5 & 32.6 & 41.1 \\
\hline $\begin{array}{l}\text { Nurses have } \\
\text { opportunities to } \\
\text { participate in decisions } \\
\text { that affect centre } \\
\text { policies. }\end{array}$ & --- & --- & 54.2 & 50.6 \\
\hline
\end{tabular}

2

3

4 
Figure 1

Selection (\%) of each element in the PES-NWI questionnaire (numbers correspond to the item number in the original scale).

The figure shows, in \% order, the frequency of the choices of each one by the nurses who participate in the study. Above $40 \%$ of elections there are a total of 10 elements of the PESNWI questionnaire. 


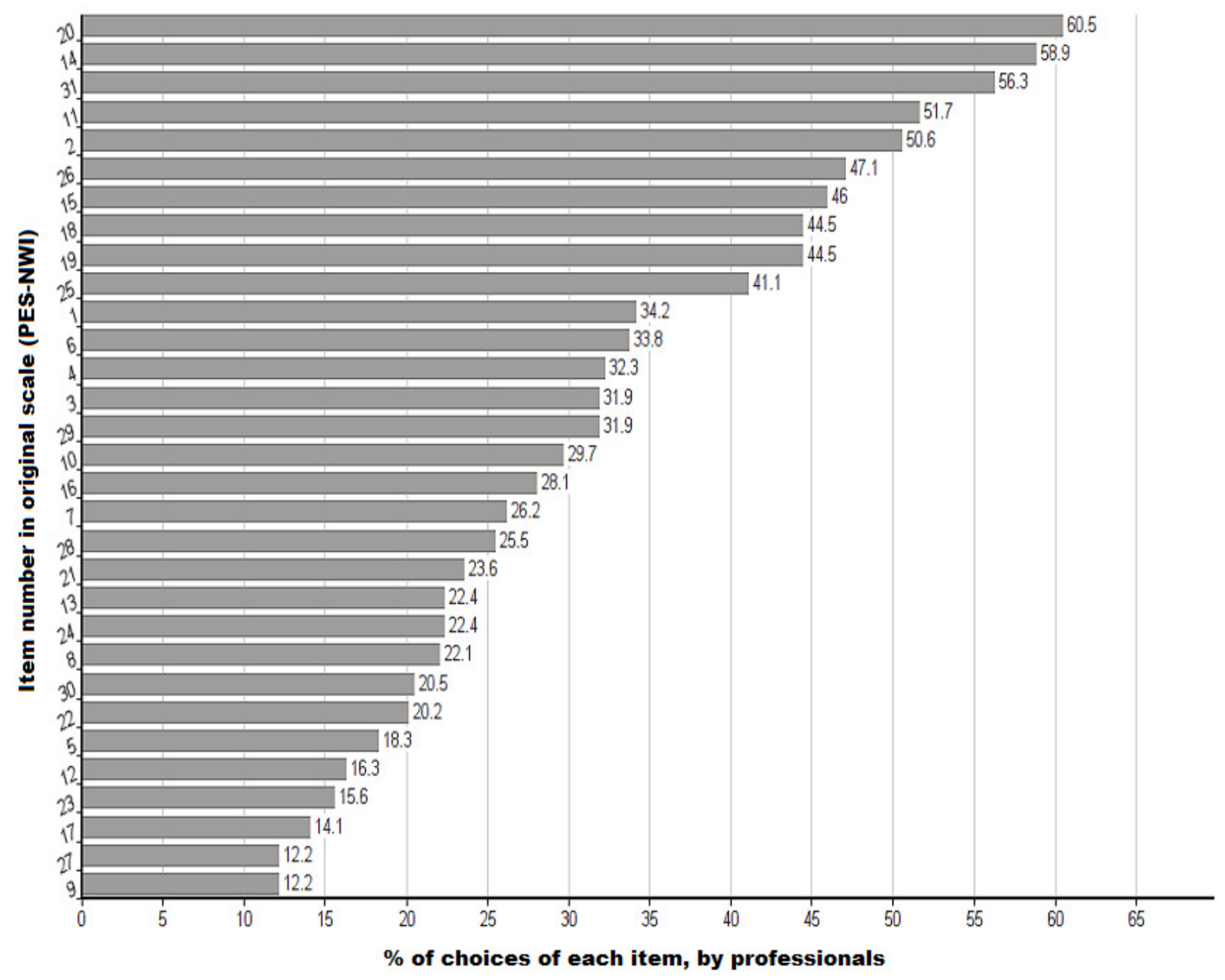


Figure 2

Concordance analysis between TOP10 and PES-NWI: Bland-Altman method.

The scatter plot allows to observe the high concordance between both measurements, one with the complete PES-NWI questionnaire, and with the abbreviated questionnaire TOP10. 


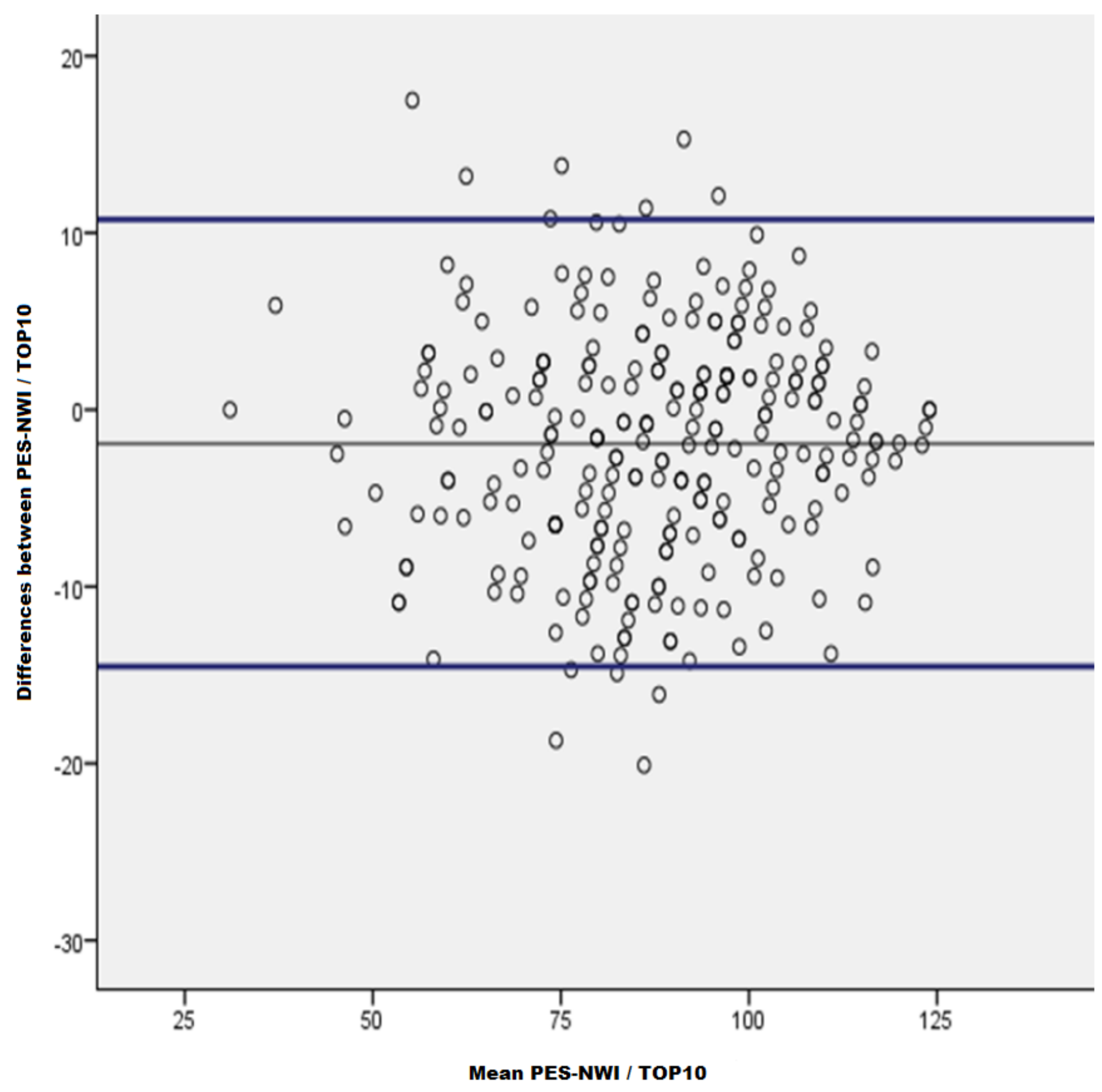

